\title{
Endocrine responses of goats after induction of superovulation with PMSG and FSH
}

\author{
D. T. Armstrong*, A. P. Pfitzner, G. M. Warnes, M. M. Ralph and \\ R. F. Seamark
}

${ }^{*}$ M.R.C. Group in Reproductive Biology, and *Departments of Physiology and Obstetrics \& Gynaecology, The University of Western Ontario, London, Canada and Department of Obstetrics \& Gynaecology, Queen Elizabeth Hospital, University of Adelaide, Adelaide, South Australia 5011

\begin{abstract}
Summary. Goats in Group A were pretreated for 9 days with a synthetic progestagen, administered via intravaginal sponge, and 1000 i.u. PMSG s.c. on Day 12 of the oestrous cycle. Goats in Group B had the same PMSG treatment, but not the progestagen pretreatment. Group $\mathrm{C}$ goats received a s.c. twice daily injection of a porcine FSH preparation (8 mg on Day 12, $4 \mathrm{mg}$ Day 13, $2 \mathrm{mg}$ Day 14 and $1 \mathrm{mg}$ Day 15). Oestrus was synchronized in all animals by $50 \mu \mathrm{g}$ cloprostenol, 2 days after the start of gonadotrophin treatment. The vaginal progestagen sponges were removed from Group A at the same time. Mean ovulation rate was slightly higher in FSH-treated than in the PMSG-treated animals, whereas the incidence of large follicles that failed to ovulate was significantly elevated in PMSG-treated animals in Group B. More goats in Groups A and B than in Group C exhibited premature luteal failure. Progestagen pretreatment appeared to suppress both follicular and luteal activity, as indicated by numbers of large non-ovulating follicles and by the magnitude and duration of elevated plasma oestradiol levels following PMSG stimulation, and by decreased plasma progesterone levels before and after PMSG treatment. Oestrogenic response to FSH was considerably less than that to PMSG, as indicated both by a considerably shorter duration of elevation of circulating oestradiol levels during the peri-ovulatory period, and by lower maximal oestradiol levels. Differences in the ovarian responses to PMSG and FSH may be attributed primarily to differences in the biological half-life of each preparation.
\end{abstract}

\section{Introduction}

Pregnant mare's serum gonadotrophin (PMSG) has been used widely as a means of inducing ovulation and superovulation in laboratory animals and for purposes of genetic improvement of livestock in conjunction with embryo transfer techniques. There are numerous reports of extreme variability and poor predictability of response of domestic animals to this gonadotrophin (see review by Betteridge, 1977). Our previous attempts to induce superovulation in goats with PMSG have led to disappointing ovulation rates, and a high incidence of large follicles which failed to ovulate (Armstrong et al., 1982): other factors which may have contributed to the poor ovulatory response to PMSG were a rather prolonged pretreatment ( 3 weeks) with a synthetic progestagen immediately before administration of the gonadotrophin. In addition, the studies were done outside the normal breeding season. 
Moore \& Eppleston (1979) obtained better ovulation rates (13.7 per female) in a small series of PMSG-treated Angora goats during the breeding season, but fertilization of the ovulated eggs was low $(46 \%)$. In a larger series of Angoras treated with a crude equine pituitary gonadotrophin preparation, these authors obtained an essentially similar ovulation rate (10.4 per female) but a better fertilization rate $(73 \%)$. The persistence of large, unovulated follicles was similar in the two studies and this may be a reflection of the rather similar long half-life and other biological similarities between horse pituitary gonadotrophin and PMSG (Parlow, 1963; Licht et al., 1979).

In an attempt to gain further understanding of the nature of the goat's response to gonadotrophic stimulation, the present studies were undertaken to evaluate endocrine responses of ovaries during the pre-ovulatory and early post-ovulatory periods in goats subjected to various superovulatory regimens. The effect of pretreatment with intravaginal progestagen sponges on response to PMSG was determined. In addition, a comparison was made of PMSG with a porcine follicle-stimulating hormone (FSH) preparation, a pituitary FSH which has a considerably shorter half-life (Parlow \& Reichert, 1963).

\section{Materials and Methods}

Feral goats of mixed ancestry, kept under domesticated conditions for at least 1 year, were used. Vasectomized males, wearing harnesses equipped with marking crayons, were run with the females, and observations were made twice daily to determine oestrus.

After each female had exhibited at least one oestrous period during the breeding season, the females were assigned at random to 3 groups of 8 per group. Nanny-goats in Group A had progestagen-impregnated vaginal sponges (6 $\alpha$-methyl-17 $\alpha$-acetoxyprogesterone, $60 \mathrm{mg}$; Repromap: Upjohn, Kalamazoo, U.S.A.) inserted on Day 3 of their cycle, and were left for 9 days before treatment with gonadotrophin. Females in Groups B and C did not receive intravaginal sponges. Each female in Groups A and B received a s.c. injection of 1000 i.u. PMSG (Folligon: Intervet, Artarmon, Australia) on Day 12 of the cycle (i.e. 9 days after insertion of sponges in Group A). After 2 days the sponges were removed from Group A animals, and a luteolytic injection of the prostaglandin F-2 $\alpha$ analogue, cloprostenol (Estrumate: I.C.I., Macclesfield, U.K.) $(50 \mu \mathrm{g}$, i.m.) was given to Groups A and B. Females in Group C were treated with a porcine pituitary FSH preparation (FSH-P; Burns, Omaha, U.S.A.), of known FSH potency and LH contamination (see 'Results'). Because of its short half-life, it was injected s.c. twice daily over the 4-day period beginning 2 days before cloprostenol administration. In an attempt to approximate the type of stimulation obtained with the single PMSG injections, the FSH was administered on a decreasing dosage regimen of $8,4,2$ and $1 \mathrm{mg}$ on 4 successive days, each day's dosage being divided into two equal doses administered $12 \mathrm{~h}$ apart. Cloprostenol $(50 \mu \mathrm{g}, \mathrm{i} . \mathrm{m}$.) was given on the morning of the $3 \mathrm{rd}$ day.

Blood samples were collected by jugular venepuncture into tubes containing EDTA or heparin. Daily samples were obtained from each goat beginning at the time of gonadotrophin administration. Twice daily sampling was begun at the time of cloprostenol administration and continued until animals had come into and gone out of oestrus; at this time sampling frequency was decreased again to once daily, until 5 days after onset of oestrus. Plasma was removed by centrifugation and samples were stored at $-20^{\circ} \mathrm{C}$ until assayed for oestradiol-17 $\beta$, progesterone or luteinizing hormone ( $\mathrm{LH})$.

Progesterone and oestradiol-17 $\beta$ were measured by radioimmunoassay (RIA) procedures which used ${ }^{3} \mathrm{H}$-tracers and polyethylene glycol 6000 for precipitation of the bound steroid (Kerin et al., 1981). Antisera were prepared against oestradiol-17 $\beta$ and progesterone by immunizing goats against oestradiol-17 $\beta-6-(\mathrm{O}$-carboxymethyl)-oxime-bovine gamma globulin and progesterone-11 $\alpha$ hemisuccinate-bovine gamma globulin, respectively. The method of Abraham (1969) was used to determine cross-reactivity. The percentage cross-reactivity of the oestradiol antisera at a dilution of 
$1: 20000$ was $100 \%$ with oestradiol- $17 \beta, 17 \%$ with oestrone, $1.1 \%$ with oestriol, and $<0.02 \%$ with progesterone, cortisol, testosterone and androstenedione. The percentage cross-reactivity of the progesterone antiserum, at a dilution of $1: 7000$, was $100 \%$ with progesterone, $1 \cdot 2 \%$ with $17 \alpha-\mathrm{OH}-$ progesterone, $0.44 \%$ with pregnenolone, $0.17 \%$ with $20 \alpha-\mathrm{OH}$-pregn-4-en-3-one and $<0.05 \%$ with oestradiol-17 $\beta$, cortisol, testosterone and androstenedione.

For oestradiol- $17 \beta$ assays, $0 \cdot 5-1 \cdot 0 \mathrm{ml}$ plasma were extracted with diethyl ether : ethyl acetate $(1: 1 \mathrm{v} / \mathrm{v})$. The serum was fozen at $-30^{\circ} \mathrm{C}$, the solvent decanted into assay tubes and evaporated, and the residue assayed directly without further purification. Sensitivity, determined statistically for each assay, was in the range of $10 \mathrm{pg} / \mathrm{ml}$ when $1 \mathrm{ml}$ samples of plasma were assayed.

For progesterone assays, serum was extracted with heptane :ethylacetate $(4: 1 \mathrm{v} / \mathrm{v})$, and duplicate aliquants of a single extract were assayed. The detection limit for progesterone assays was $0.5 \mathrm{ng} / \mathrm{ml}$. The intra- and inter-assay coefficients of variation for both steroid assays were $<10 \%$ and $<20 \%$, respectively.

Immunoreactive LH activity was measured in plasma by RIA procedures as described by Niswender, Reichert, Midgley \& Nalbandov (1969) using the rabbit anti-ovine LH serum (no. 15) provided by Dr G. D. Niswender, highly purified ovine LH (LER1056-C2) for iodination provided by Dr L. E. Reichert, Jr, and NIH-LH-S19 as standard. Sensitivity was $<0.25 \mathrm{ng} / \mathrm{ml}$. Intra- and inter-assay coefficients of variation at $1.6 \mathrm{ng} / \mathrm{ml}$ were $15 \%$ and $22 \%$, respectively.

Ovaries were examined by mid-ventral laparotomies, performed 5-9 days after onset of oestrus, to determine ovulation rates, degree of excessive follicle stimulation, and functional state of corpora lutea, as determined by size and colour (Armstrong et al., 1982).

Student's $t$ tests were used to assess significance of differences between means (Steel \& Torrie, 1960).

\section{Results}

\section{Ovarian responses}

Oestrus was detected in 6 of the 8 females in Group A and in 7 of 8 in each of Groups B and C. In 3 of the 4 females that failed to exhibit oestrus, the ovaries responded to the gonadotrophin treatment with multiple ovulation. The fourth, which was in Group B (PMSG + cloprostenol), failed to ovulate, although there were signs of follicular stimulation and the endocrine responses were not markedly different from those of other animals in the same group. This goat was therefore included in subsequent analyses. The time of onset of oestrus varied from 0 to 3 days after administration of cloprostenol to induce luteolysis, but the mean time of onset and duration of oestrus did not differ amongst the three treatment groups (Table 1).

Variability in ovulation rate was high in all three treatment groups, ranging from 5 to 17 for Group A, 0 to 21 for Group B, and 4 to 49 for Group C (Table 1). Because of this high degree of variability, no conclusion could be drawn concerning superiority of one treatment over another,

Table 1. Ovarian responses of goats to treatments for induction of superovulation

\begin{tabular}{|c|c|c|c|c|c|c|}
\hline \multirow[b]{2}{*}{ Group } & \multirow[b]{2}{*}{$\begin{array}{l}\text { No. of } \\
\text { females }\end{array}$} & \multicolumn{2}{|c|}{ Oestrus } & \multicolumn{2}{|c|}{ No. per female } & \multirow[b]{2}{*}{$\begin{array}{c}\text { No. of females } \\
\text { with } \\
\text { maintained CL }\end{array}$} \\
\hline & & $\begin{array}{c}\text { Onset } \\
\text { (days after } \\
\text { cloprostenol) }\end{array}$ & $\begin{array}{c}\text { Duration } \\
\text { (days) }\end{array}$ & Ovulations & $\begin{array}{c}\text { Large } \\
\text { follicles }\end{array}$ & \\
\hline A (sponge + PMSG) & 8 & $1 \cdot 3 \pm 0.2$ & $1 \cdot 2 \pm 0.2$ & $10 \cdot 5 \pm 1 \cdot 5$ & $5.8 \pm 1.9$ & 2 \\
\hline $\mathrm{B}$ (PMSG) & 8 & $1.6 \pm 0.3$ & $1.7 \pm 0.2$ & $10 \cdot 1 \pm 3 \cdot 0$ & $14 \cdot 5 \pm 2 \cdot 4^{*}$ & 1 \\
\hline $\mathrm{C}(\mathrm{FSH})$ & 8 & $1 \cdot 7 \pm 0.4$ & $1.7 \pm 0.4$ & $17 \cdot 6 \pm 5 \cdot 5$ & $4.4 \pm 1.9$ & 7 \\
\hline
\end{tabular}

Values are mean \pm s.e.m.

* Significantly different from Group $C$ value $(P<0.05)$, but not from Group A value $(P>0.05)$. 
even though mean ovulation rate in Group C (FSH) was considerably greater than that in Groups A and B (PMSG). The highest number of large follicles ( $>6 \mathrm{~mm}$ diameter) was observed in Group B and the lowest in Group C. Pretreatment with intravaginal progestagen (Group A) tended to decrease the number of large follicles, but the difference between Groups A and B was not statistically significant.

Based on gross appearance at the time of laparotomy, corpora lutea were not maintained in the majority of PMSG-treated animals (13 out of 16) irrespective of prior progestagen treatment, whereas luteal failure was observed in only 1 of the 8 FSH-treated animals $(P<0 \cdot 01)$. The diagnosis of luteal failure was based on corpora appearing small, and white or light pink, as distinct from rich red, highly vascular appearance of functional corpora lutea. Their lack of functional activity was borne out by the observations that 4 of the animals in Group A and 2 in Group B had returned to oestrus and/or ovulated a second batch of follicles by the time of laparotomy.

\section{Hormone changes}

These are shown for a representative animal in each group in Text-fig. 1.

Mean plasma progesterone concentrations at three specific times during treatment, are presented in Table 2. Plasma progesterone concentrations in Group A animals were significantly lower than those in Group B animals when gonadotrophin treatment was begun, and after 2 days of exposure to PMSG $(P<0.05)$, suggesting a negative feedback effect of the progestagen in

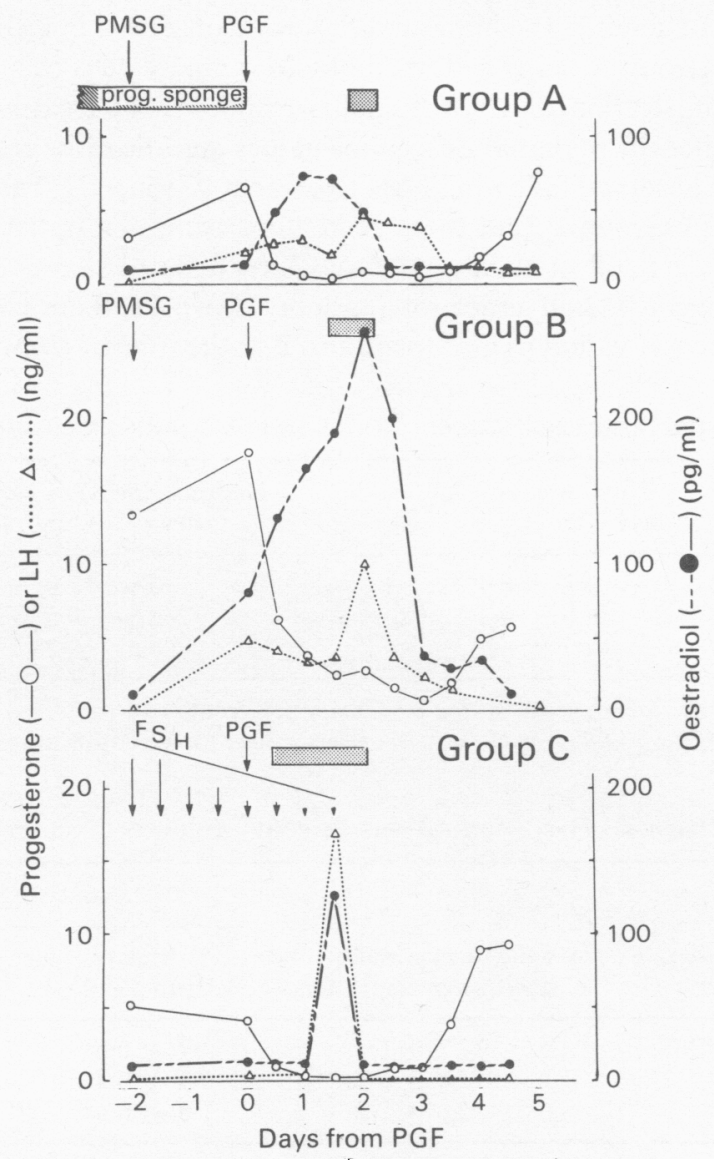

Text-fig. 1. Plasma concentrations of progesterone, oestradiol and LH in representative animals in Groups A, B and C. The stippled bar indicates oestrus. 
Table 2. Plasma progesterone concentration in goats induced to superovulate

\begin{tabular}{lccc}
\hline & \multicolumn{3}{c}{ Progesterone $(\mathrm{ng} / \mathrm{ml})$ at time of: } \\
\cline { 2 - 4 } \multicolumn{1}{c}{ Group } & $\begin{array}{c}\text { Start of gonadotrophin } \\
\text { treatment }\end{array}$ & $\begin{array}{c}\text { Cloprostenol } \\
\text { treatment }\end{array}$ & $\begin{array}{c}\text { Onset of } \\
\text { oestrus }\end{array}$ \\
\hline A (sponge + PMSG) & $3.6 \pm 0.7^{*}$ & $6 \cdot 2 \pm 1 \cdot 2 \dagger$ & $1.5 \pm 0.8$ \\
B (PMSG) & $7 \cdot 7 \pm 1 \cdot 2$ & $11 \cdot 3 \pm 1 \cdot 7 \dagger$ & $1.6 \pm 0.3$ \\
C (FSH) & $7 \cdot 1 \pm 1.0$ & $7.3 \pm 1.4$ & $0.8 \pm 0.1$ \\
\hline
\end{tabular}

Values are mean \pm s.e.m. for 8 animals per group. $0.05)$.

* Significantly lower than corresponding values for Groups B and C $(P<$

$\dagger$ Significantly greater than levels observed in the same treatment group at start of gonadotrophin treatment $(P<0.05$, paired $t$ test).

controlling levels of luteal activity. Circulating progesterone levels were significantly $(P<0.05)$ increased by the action of PMSG, irrespective of whether they were suppressed by the progestagen sponge. In contrast, no significant effect of FSH on plasma levels of progesterone was noted. Cloprostenol treatment was as effective in reducing plasma progesterone levels in all three treatment groups; there were no significant differences at the time of onset of oestrus.

Plasma oestradiol levels were highly variable, but some patterns were seen which could be attributed to treatment. In general, the highest values were observed in Group B and the lowest in Group C, with those of Group A being intermediate. Maximal values occurred at a mean time of 1.7-1.8 days after administration of cloprostenol, irrespective of treatment. PMSG treatment (Groups A and B) resulted in maximal oestradiol values significantly greater and lasting for a longer period than those observed following FSH treatment (Group C) (Table 3). Values in Group A were less than those in Group B, but these reductions were not statistically significant.

Since blood samples were collected only at $0 \cdot 5$-day intervals, the shapes of the preovulatory $\mathrm{LH}$ surges at best can only be considered as approximations. However, there were some distinct group differences (Table 4). The LH values in Groups A and B at the time of cloprostenol administration

Table 3. Plasma oestradiol concentrations in goats induced to superovulate

\begin{tabular}{lccr}
\hline \multicolumn{1}{c}{ Group } & $\begin{array}{c}\text { Time of max. conc. } \\
\text { (days after cloprostenol) }\end{array}$ & $\begin{array}{c}\text { Duration (days) of elevated } \\
\text { values }(>30 \mathrm{pg} / \mathrm{ml})\end{array}$ & $\begin{array}{c}\text { Maximal value } \\
(\mathrm{pg} / \mathrm{ml})\end{array}$ \\
\hline A (sponge + PMSG) & $1.8 \pm 0.4$ & $2 \cdot 8 \pm 1 \cdot 0$ & $103 \pm 24$ \\
B (PMSG) & $1.8 \pm 0.2$ & $3.6 \pm 0.6$ & $138 \pm 23$ \\
C (FSH) & $1.7 \pm 0.4$ & $0.5 \pm 0.2^{*}$ & $53 \pm 12^{*}$ \\
\hline
\end{tabular}

Values are mean \pm s.e.m. for 8 animals per group.

* Significantly different $(P<0.01)$ from values for Group B animals.

Table 4. Plasma LH concentrations in goats induced to superovulate

\begin{tabular}{lccc}
\hline & & \multicolumn{2}{c}{ LH conc. (ng./ml) } \\
\cline { 3 - 4 } \multicolumn{1}{c}{ Group } & Time of maximum conc. & At time of & Max. \\
(days after cloprostenol) & cloprostenol & value \\
\hline A (sponge + PMSG) & $1 \cdot 7 \pm 0 \cdot 3$ & $3 \cdot 7 \pm 0 \cdot 5$ & $7 \cdot 0 \pm 3 \cdot 4$ \\
B (PMSG) & $2 \cdot 4 \pm 0 \cdot 2$ & $3 \cdot 3 \pm 0 \cdot 4$ & $4 \cdot 1 \pm 1 \cdot 2$ \\
C (FSH) & $2 \cdot 6 \pm 0 \cdot 4$ & $1 \cdot 6 \pm 0 \cdot 4^{*}$ & $21 \cdot 6 \pm 6 \cdot 8^{*}$ \\
\hline
\end{tabular}

Values are mean \pm s.e.m. for 8 animals per group.

* Significantly different from values in Group A and B animals $(P<0.05)$. 
(i.e. at the time of the signal for, and therefore well before, the $\mathrm{LH}$ surge) were significantly greater than those in Group $\mathrm{C}$ animals $(P<0.02)$, presumably because of the $\mathrm{LH}$ activity inherent in the PMSG, and the considerably longer half-life of PMSG than of the porcine pituitary gonadotrophin(s). The times of LH maxima did not differ significantly amongst treatments but the apparent maximal LH levels varied greatly within each treatment group, undoubtedly because of the low probability of observing the actual maxima with 12-h sampling intervals. However, the maximal observed values in Group $C$ were significantly greater $(P<0.05)$ than those in Groups A and $\mathbf{B}$.

\section{Characterization of gonadotrophin preparations}

The relative FSH potencies of the PMSG and FSH were determined in an FSH radioreceptor assay using a bovine testes membrane preparation and ${ }^{125}$ I-labelled human FSH as tracer (Cheng, 1975). The FSH potency of the PMSG, expressed in terms of the NIH-FSH-S10 (ovine) standard, was $387 \pm 67 \mathrm{ng} /$ i.u. (mean \pm s.e. of 5 separate assays). The FSH potency of the porcine FSH in the same assays was $530 \pm 68 \mathrm{ng} / \mu \mathrm{g}$ (mean \pm s.e. of 4 separate assays). Therefore, the total FSH dosage of $15 \mathrm{mg}$ administered in 8 injections over a 4-day period represents $7.95 \mathrm{mg}$ FSH standard, whereas the comparable value for the dose of PMSG (1000 i.u.) administered as a single injection represents only $0.39 \mathrm{mg}$, or $1 / 20$ the dosage in terms of the NIH standard.

The relative LH potencies of the PMSG and FSH preparations were determined in an LH radioimmunoassay, using an anti-ovine $\mathrm{LH}$ serum prepared in a rabbit, and ${ }^{125}$ I-labelled ovine $\mathrm{LH}$ as trace. The LH potencies were $0.071 \mu \mathrm{g}$ NIH-LH-S8/i.u. for the PMSG and 0.125 $\mu \mathrm{g} \mathrm{NIH-LH-}$ $\mathrm{S} 8 / \mathrm{\mu g}$ for the FSH, and the FSH : $\mathrm{LH}$ ratios of the two gonadotrophin preparations, as determined in these radioligand assays, did not differ markedly (5.45 and 4.24 for PMSG and FSH, respectively).

\section{Discussion}

The dosages of PMSG and porcine FSH used in this study proved effective in inducing superovulation in goats, although considerable variability of responses to both gonadotrophins was noted. These dosages were arrived at on the basis of preliminary tests with various doses. The effective dose of PMSG (1000 i.u.) contained much less FSH activity as evaluated in a bovine testis radioreceptor assay than the equivalent effective dose of porcine FSH ( $15 \mathrm{mg}$ total dose). The great difference in ovulation-inducing ability could not be attributed to major differences in LH activity, as both preparations contained about equivalent $\mathrm{LH}$ immunoreactivity relative to their FSH radioreceptor activity. It seems most likely, then, that the much greater effectiveness of the PMSG, in terms of its FSH activity, is due to its considerably longer biological half-life (approx. $20 \mathrm{~h}$ for PMSG, compared with $2 \mathrm{~h}$ or less for FSH) (Akbar, Nett \& Niswender, 1974; McIntosh, Moor \& Allen, 1975).

The difference in half-life may be the cause of several other differences in ovarian responses to the two gonadotrophins. For example, it seems likely that the higher incidence of large follicles which failed to ovulate in the PMSG-treated females was due to continued recruitment of follicles, as a result of persisting high circulating PMSG levels. Related to this are the higher levels of plasma oestradiol, which persisted considerably longer in the PMSG-treated, than in the FSH-treated females. Whether the higher incidence of luteal failure was also attributable to the prolonged circulating levels of PMSG is not certain. It is possible that endogenous prostaglandin F-2 $\alpha$ of follicular (arising from the highly stimulated follicles that fail to ovulate) or uterine origin (in response to prolonged stimulation by elevated circulating levels of oestradiol) may be a causative factor in the premature luteal failure, via its well-established luteolytic action. However, it is uncertain whether the defective luteal phase was the result of premature luteolysis, or of failure of 
the corpora lutea to become functional following superovulation with PMSG, as blood sampling was not continued for long enough during the post-ovulatory period to enable results of plasma progesterone determination to distinguish between these two possibilities.

Pretreatment with the synthetic progestagen, $6 \alpha$-methyl-17 $\alpha$-acetoxyprogesterone, appeared to suppress both follicular and luteal activity, as indicated by the tendency toward fewer large follicles and lower maximal oestradiol levels in PMSG-treated females, and by depressed plasma progesterone levels before and after stimulation with PMSG. It is not clear whether these effects represent suppression at the ovarian level, or whether they are due to a negative feedback effect on the secretion by the pituitary of follicle-stimulating and luteotrophic hormones. The effectiveness of PMSG in increasing plasma progesterone in the presence as well as in the absence of the synthetic progestagen argues in support of the inhibitory effect on progesterone secretion as being mediated via inhibition at the level of the pituitary gland, presumably of LH secretion, since LH is the essential pituitary luteotrophic hormone in the goat (Buttle, 1978).

The tendency toward greater ovulation rate and decreased incidence of premature luteal regression in the FSH-treated than in the PMSG-treated goats in the present study led us to compare these two gonadotrophin preparations in a larger series of Angora goats, as a means of inducing superovulation in an embryo transfer programme. The superiority of FSH over PMSG has been borne out both in numbers of ovulations and in numbers of offspring born to recipients following embryo transfer (Armstrong, Pfitzner, Warnes \& Seamark, 1983).

We are grateful to Dr Alan Cotton and Colchis Angora Stud, Nairne, South Australia, for providing the goats used in this research, which was supported by the M.R.C. of Canada and the Endocrine Fund, Queen Elizabeth Hospital, Adelaide. D.T.A. is a Career Investigator of the M.R.C. of Canada.

\section{References}

Abraham, G.D. (1969) Solid phase radioimmunoassay of oestradiol-17ß. J. clin. Endocr. Metab. 29, 866-870.

Akbar, A.M., Nett, R.M. \& Niswender, G.D. (1974) Metabolic clearance and secretion rates of gonadotropins at different stages of the estrous cycle in ewes. Endocrinology 94, 1318-1324.

Armstrong, D.T., Pfitzmer, A.P., Porter, K.J., Warnes, G.M., Janson, P.O. \& Seamark, R.F. (1982) Ovarian responses of anestrous goats to stimulation with pregnant mare serum gonadotropin. Anim. Reprod. Sci. 5, 15-23.

Armstrong, D.T., Pfitmer, A.P., Warnes, G.M. \& Seamark, R.F. (1983) Superovulation treatments and embryo transfer in Angora goats. J. Reprod. Fert. 67, 403-410.

Betteridge, K.J. (1977) Superovulation. In Embryo Transfer in Farm Animals, pp. 1-9. Ed. K. J. Betteridge. Canada Dept. of Agriculture Monograph 16, Ottawa.

Buttle, H.L. (1978) The maintenance of pregnancy in hypophysectomized goats. J. Reprod. Fert. 52, 255260.

Cheng, K.-W. (1975) A radioreceptor assay for folliclestimulating hormone. J. clin. Endocr. Metab. 41, 581589.

Kerin, J.F., Broom, T.J., Ralph, M.M., Edwards, D.K., Warnes, G.M., Jefirey, R., Crocker, J.M., Godfrey, B., Cox, L.W., Seamark, R.F. \& Matthews, C.D.
(1981) Human luteal phase function following oocyte aspiration from the immediately preovular Graafian follicle or spontaneous ovular cycles. Br. J. Obstet. Gynaecol. 88, 1021-1028.

Licht, P., Bona-Gallo, A., Aggarwal, B.B., Farmer, S.W., Castelino, J.B. \& Papkoff, H. (1979) Biological and binding activities of equine pituitary gonadotrophin and pregnant mare serum gonadotrophin. J. Endocr. 83, 311-322.

MeIntosh, J.E.A., Moor, R.M. \& Allen, W.R. (1975) Pregnant mare serum gonadotrophin: rate of clearance from the circulation of sheep. J. Reprod. Fert. 44, 95-100.

Moore, N.W. \& Eppleston, J. (1979) Embryo transfer in the Angora goat. Aust. J. agric. Res. 30, 973-981.

Niswender, G.D., Reichert, L.E., Jr, Midgley, A.R., Jr, \& Nalbandov, A.V. (1969) Radioimmunoassay for bovine and ovine luteinizing hormone. Endocrinology 84, 1166-1173.

Parlow, A.F. (1963) Species differences in luteinizing hormone as revealed by the slope in the prostate assay. Endocrinology 73, 509-512.

Parlow, A.F. \& Reichert, L.E. (1963) Species differences in follicle-stimulating hormone as revealed by the slope in the Steelman Pohley assay. Endocrinology 73, $740-743$.

Steel, R.G.D. \& Torrie, J.H. (1960) Principles and Procedures of Statistics. McGraw-Hill, New York. 